\title{
Minimally invasive and robotic coronary artery bypass grafting-a 25-year review
}

\author{
Johannes Bonatti ${ }^{1}$, Stephanie Wallner ${ }^{1}$, Ingo Crailsheim ${ }^{1}$, Martin Grabenwöger $^{1,2}$, Bernhard Winkler ${ }^{1,3}$ \\ ${ }^{1}$ Department of Cardiac and Vascular Surgery, Vienna Health Network, Clinic Floridsdorf and Karl Landsteiner Institute of Cardiovascular Surgical \\ Research, Vienna, Austria; ${ }^{2}$ Medical Faculty, Sigmund Freud University, Vienna, Austria; ${ }^{3}$ Center for Biomedical Research, Medical University of \\ Vienna, Vienna, Austria \\ Contributions: (I) Conception and design: All authors; (II) Administrative support: All authors; (III) Provision of study materials or patients: All \\ authors; (IV) Collection and assembly of data: All authors; (V) Data analysis and interpretation: All authors; (VI) Manuscript writing: All authors; (VII) \\ Final approval of manuscript: All authors. \\ Correspondence to: Johannes Bonatti, MD, FETCS. Cardiac Surgeon, Associate Professor of Surgery, Department of Cardiac and Vascular Surgery, \\ Vienna Health Network, Clinic Floridsdorf and Karl Landsteiner Institute of Cardiovascular Surgical Research, Brünner Strasse 68, 1210 Vienna, \\ Austria. Email: johannes.bonatti@gesundheitsverbund.at; johannes@bonatti.at.
}

\begin{abstract}
During the mid-1990s cardiac surgery started exploring minimally invasive methods for coronary artery bypass grafting (CABG) and has over a 25-year period developed highly differentiated and less traumatic operations. Instead of the traditional sternotomy mini-incisions on the chest or ports are placed, surgery on the beating heart is applied, sophisticated remote access heart lung machine systems as well as videoscopic units are available, and robotic technology enables completely endoscopic approaches. This review describes these methods, reports on the cumulative intra- and postoperative outcome of these procedures, and gives an integrated view on what less invasive coronary bypass surgery can achieve. A total of 74 patient series published on the topic between 1996 and 2019 were reviewed. Six main versions of minimal access and robotically assisted CABG were applied in 11,135 patients. On average $1.3 \pm 0.6$ grafts were placed and the operative time was 3 hours $42 \mathrm{~min} \pm 1$ hour $15 \mathrm{~min}$. The procedures were carried out with a hospital mortality of $1.0 \%$ and a stroke rate of $0.6 \%$. The revision rate for bleeding was $2.5 \%$ and a renal failure rate of $0.9 \%$ was noted. Wound infections occurred at a rate of $1.2 \%$ and postoperative hospital stay was $5.6 \pm 2.2$ days. It can be concluded that less invasive and robotically assisted versions of coronary bypass grafting are carried out with an adequate safety level while surgical trauma is significantly reduced.
\end{abstract}

Keywords: Coronary artery bypass grafting (CABG); minimally invasive; remote access heart lung machine; robotic surgery; totally endoscopic coronary bypass

Submitted Mar 31, 2020. Accepted for publication Sep 18, 2020.

doi: $10.21037 /$ jtd-20-1535

View this article at: http://dx.doi.org/10.21037/jtd-20-1535

\section{Introduction}

Based on the successes of general surgery, gynecology, urology, and thoracic surgery in the creation of video assisted, laparoscopic or thoracoscopic procedures heart surgery approached minimally invasive versions of its procedures in the mid-1990s. At that time a definition of what less invasive surgery would mean for cardiac surgery was searched. Two main questions were part of this discussion: how to limit the thoracic incision and how to limit the use of cardiopulmonary bypass. For coronary artery bypass grafting (CABG) versions of beating heart surgery without the heart lung machine had already been developed and off-pump CABG through sternotomy had been carried out primarily in South America (1). Benetti from Buenos Aires in 1994 was the first to perform a left internal mammary artery (LIMA) bypass graft to the left anterior descending (LAD) artery on the beating heart through a left sided mini-thoracotomy and with the use 
of thoracoscopy (2). This can be regarded as the advent of minimally invasive CABG. Since then different versions of minimally invasive approaches have been developed and heart surgery looks back to 25 years of valuable development.

\section{Aim}

In this review we present these methods, describe the surgical techniques, report on results as available in the literature, and provide opinions about the general applicability in clinical practice. Lastly, we present an overall picture of what minimally invasive CABG can offer for patients and the community of cardiac surgeons and cardiologists.

\section{Methods}

We analyzed literature as available from the study group's own papers and literature collections. We also queried PubMed for the search-terms "minimally invasive coronary bypass", "minimal invasive coronary bypass", "coronary bypass through mini-thoracotomy", "less invasive coronary bypass", "robotic coronary bypass", "total endoscopic coronary bypass", totally endoscopic coronary bypass", "robotically assisted coronary bypass", and "port-access coronary bypass". Also, the terms minimally invasive direct coronary artery bypass (MIDCAB), minimally invasive cardiac surgery-CABG (MICS-CABG), port-access coronary bypass grafting (PA-CABG), robotically assisted coronary artery bypass (RACAB), and totally endoscopic coronary artery bypass (TECAB) were searched. Data are presented in tables according to the most commonly used surgical methods. Only the most recent series was taken from groups publishing multiple articles on the topic. Multicenter studies and comparative studies were included in the review. For intermediate term survival the percentage of patients surviving at a given time-point was plotted against the years postoperatively. Categorical data are displayed as absolute values and percentages, continuous variables are shown as means and standard deviation as well as minimum and maximum values. For grand total means, the means out of all available studies reporting on a variable were taken.

\section{Global distribution of publications on minimally invasive coronary bypass surgery}

From 1996 to 2019, 74 articles containing series of CABG carried out minimally invasively were published. These articles contain a cumulative number of 11,135 procedures. Figure 1 shows the global distribution of these publications (Figure 1). The activities were specifically concentrated in Central Europe and the US East Coast and South, and there were also very active centers in East Asia. Six main surgical approaches were taken which will be explained and analyzed in detail. Figure 2 depicts the numerical distribution of these methods (Figure 2).

\section{Versions of minimally invasive coronary bypass surgery}

\section{Coronary bypass surgery through mini-thoracotomy on the beating heart [MIDCAB, MICS-CABG, left anterior small thoracotomy (LAST)]}

\section{Definition}

Through a mini-thoracotomy on the patient's left chest the left and/or right internal mammary arteries are harvested. Additional vein or radial artery grafts may be taken. The graft to coronary artery anastomoses are performed directly through this mini-thoracotomy on the beating heart and under direct vision using conventional surgical instrumentation. The target vessels are immobilized using suction or pressure stabilizers and the anastomoses are carried out with local coronary artery occlusion. Single or multiple grafts can be constructed.

\section{Terminology}

Most commonly the terms MIDCAB and MICS-CABG are used. Another term used is LAST.

\section{Surgical technique}

The patient is positioned supine with the left chest slightly elevated. The skin incision is usually placed below the areolar area in men and in the breast fold in women. The $4^{\text {th }}$ intercostal space is then opened. Both medial and more lateral approaches have been described. Using special metal elevators the anterior chest wall is lifted up to create space. The LIMA is harvested under direct vision using headlight and loupes. Classic coronary bypass surgery instrumentation is taken. Recent developments even allow harvesting of the right internal mammary artery (RIMA) and special retractors were developed for this part of the procedure. The pericardium is then opened and using specifically designed positioners and stabilizers the target vessels are accessed. They are after heparinization occluded 


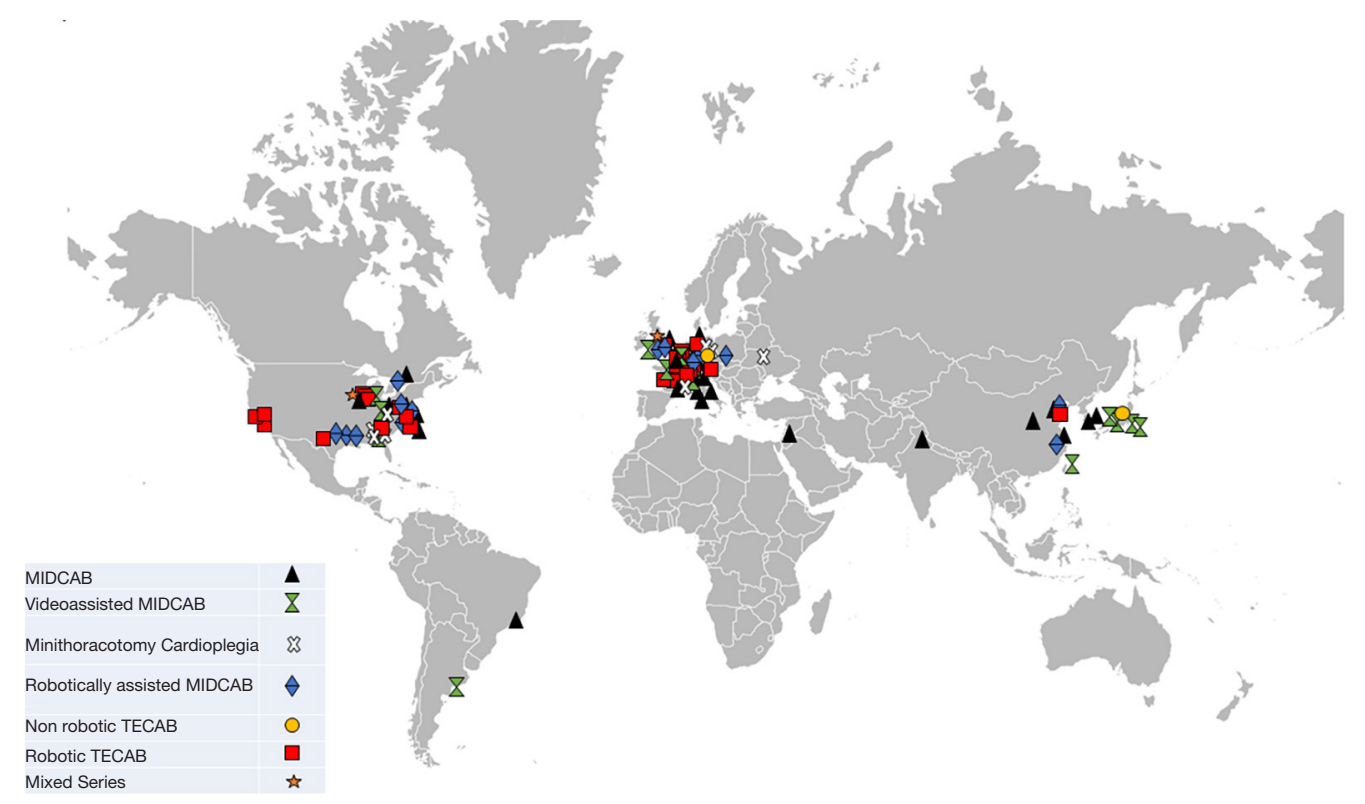

Figure 1 The global distribution of the publications reviewed in the is article is shown. The various methods are marked with different symbols. MIDCAB, minimally invasive direct coronary artery bypass; TECAB, totally endoscopic coronary artery bypass.

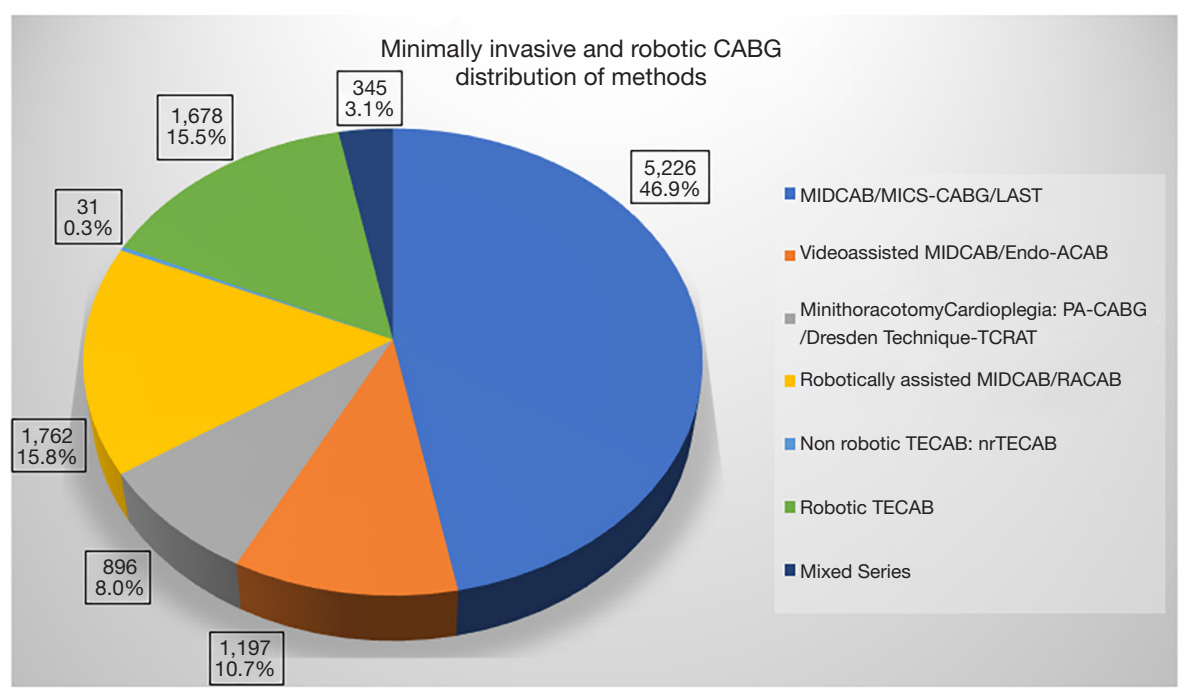

Figure 2 Numerical distribution and percentages of patients treated with the different minimally invasive surgical methods. CABG, coronary artery bypass grafting; MIDCAB, minimally invasive direct coronary artery bypass; MICS-CABG, minimally invasive cardiac surgery-CABG; LAST, left anterior small thoracotomy; endo-ACAB, endoscopic atraumatic coronary artery bypass; TCRAT, total coronary revascularization via anterior thoracotomy; RACAB, robotically assisted coronary artery bypass; TECAB, totally endoscopic coronary artery bypass; nrTECAB, non-robotic TECAB. 
using silastic tapes and incised. The anastomoses are carried out on the beating heart using standard instrumentation and standard anastomotic techniques. Intraluminal shunts may be used additionally. The internal mammary arteries are placed as in situ grafts or as Y-constructs. If vein grafts are placed the proximal anastomosis is carried out by elevating the ascending aorta using sponges. Partial occluding clamps are applied in surgical practice and the use of anastomotic connectors has been described as well.

\section{Results}

This version of minimally invasive CABG is the most commonly performed. Table 1 demonstrates that a total of 5,226 cases are part of 25 international publications written around the world (3-27) (Table 1). The table also shows that the number of grafts placed with this method has significantly increased during the last years, $76.9 \%$ of cases, however, were still single bypass grafting procedures. The total average of grafts reaches $1.2 \pm 0.6$. There is only little data on graft harvesting times. A recent paper on multivessel MICS-CABG reports $22.2 \mathrm{~min}$ for LIMA harvesting and 28.5 min for RIMA harvesting (27), probably demonstrating that work on the RIMA through a left mini-thoracotomy is feasible but more challenging than work on the LIMA. Total operative times are reported in the range from 1.1 to $5 \mathrm{~h}$. The conversion rate to larger thoracic incisions was $1.6 \%$. The overall revision rate for bleeding was $2.7 \%$ and the following rates for hard postoperative endpoints were achieved: mortality $1.0 \%$, stroke $0.5 \%$, renal failure $0.8 \%$, very acceptable rates given the innovative nature of the procedure.

\section{Comment}

Even though the MIDCAB procedure appears to be relatively simple it is technically challenging. It is a known fact that several early programs were stopped because of inferior patency rates. Leipzig Heartcenter in Germany as a highvolume center managed to get the procedure into routine application and reported 1,347 cases already in 2007 (19). The same group also evaluated learning curves and stated that a triple digit number of cases for any individual surgeon may be necessary to overcome the learning phase (28). Sophisticated simulation models are probably the only solution to dampen this problem and to guarantee adequate patient safety. The overall conversion rate to larger thoracic incisions of $1.6 \%$ reported in this cumulative literature review is very acceptable. So are the hard endpoints mortality, stroke, and renal failure given the fact that many centers reported results during their learning curves. The $1.3 \%$ wound infection rate deserves some discussion. During this procedure a mini-thoracotomy is spread for several hours and tissue malperfusion and bacterial contamination may occur. Even though the spreaders and retractors have become more refined there is still room for technological and methodological improvement in order to keep the tissue trauma at a minimum. It was a goal of the heart surgery community to reduce hospital stay by reducing invasiveness of CABG. Our review demonstrates that despite some centers sending patients home as early as 3 days postoperatively, 6 days of postoperative hospital stay are probably realistic. A cumulative 5-year survival rate of $91 \%$ (data not shown in table) appears to be in line with survival after open CABG (29).

One point of criticism for this procedure is the fact that the internal mammary arteries cannot be viewed in their whole length and sometimes grafts are placed under tension. This needs to be avoided by all means. Early papers report extension of the internal mammary artery (IMA) by a piece of saphenous vein or inferior epigastric artery in cases where tension was an issue (4). This, however, does not appear to be an ideal compromise. Another topic of discussion is the placement of a partial occluding clamp to the fully pressurized ascending aorta through a minithoracotomy. The partial occluding clamp is a risk factor of stroke in coronary bypass surgery and is in the ideal world completely avoided, and at least intraoperative imaging is a reasonable ask. Another option is the application of anastomotic connectors for the proximal anastomosis. In the authors' experience the MIDCAB procedure is ergonomically challenging with a tangential view on the IMA in single vessel MIDCAB and probably even harder access and view in bilateral IMA harvesting. Anastomotic suturing is specifically challenging in obese patients. Despite the claim of being an off-pump procedure a certain level of heart-lung machine use is probably inevitable and may even be recommended for complex cases that involve the back wall of the heart and the right coronary artery system. McGinn reported a $7.9 \%$ supportive use of the heart lung machine in his 2009 paper on the method (20).

Since the introduction of this procedure there was very justified hope that it could compete with percutaneous intervention (PCI) to the LAD. There is good evidence from several prospective randomized trials demonstrating that the MIDCAB LIMA to LAD procedure has significant advantages over percutaneous coronary intervention on the LAD concerning freedom from reintervention and 


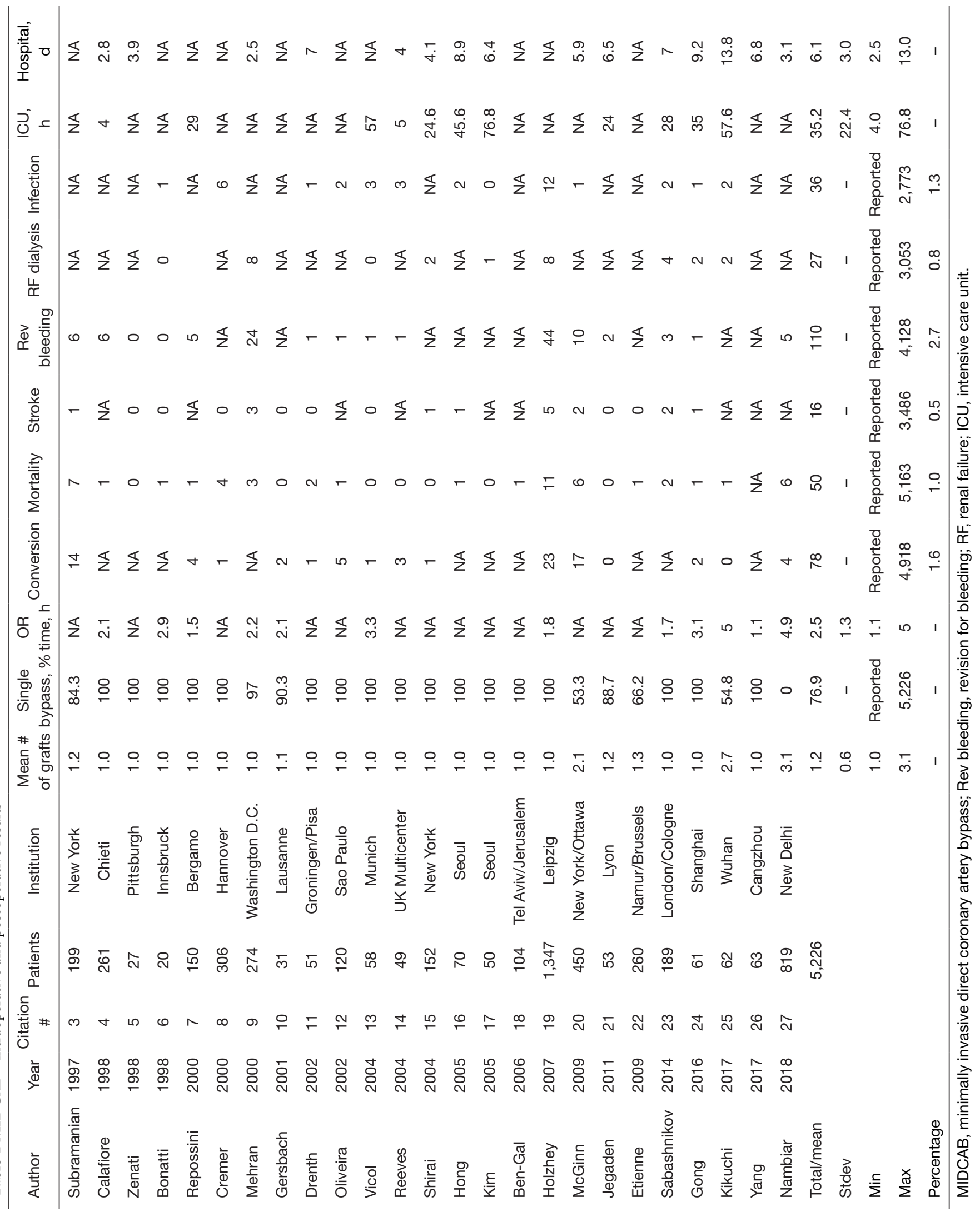


overall major adverse cardiac event (MACE) or major adverse cardiac and cerebrovascular event (MACCE) (30-32). Midterm survival, however in these studies was not significantly different.

MIDCAB is the technologically least complex of all minimally invasive $C A B G$ procedures and therefore attractive if cost for sophisticated devices is an issue. The technical challenges and learning curve should on the other hand not be underestimated. The following part of the review may highlight what the addition of videoscopic adjuncts offers.

\section{Video assisted coronary bypass on the beating heart through mini-thoracotomy [video assisted MIDCAB, endoscopic atraumatic coronary artery bypass (endo-ACAB)]}

\section{Definition}

In this version of minimally invasive CABG parts of the procedure are performed under thoracoscopic video guidance. Mostly the video assistance is only used for IMA harvesting and location of the target vessel.

\section{Terminology}

For this procedure the most commonly used abbreviations are video-assisted MIDCAB and endo-ACAB.

\section{Surgical technique}

The patient is placed in supine position even though early papers also describe a right lateral decubitus position. Left lung collapse is usually applied and a thoracoscope as well as two instrument ports are inserted on the patient's left chest. The IMA is harvested under thoracoscopic view. The harvesting is reported both in pedicled and skeletonized fashion. The literature commonly describes a version with $2 \mathrm{D}$ view and only one more recent paper reports on the use of 3D endoscopy (33). In one very early report a flexible gastroscope was taken for IMA harvesting (34). The graft to coronary anastomosis is usually performed through a minithoracotomy under direct vision on the beating heart with local target vessel stabilization and temporary coronary artery occlusion.

\section{Results}

As shown in Table 2, 1,197 cases are reported in the literature (23,33-44), $87.6 \%$ of them were single LIMA to LAD grafts. The LIMA harvesting time averaged $47.5 \pm 7.8$ min, and in the paper describing bilateral IMA harvesting the RIMA harvesting time was 54 minutes. Total operative time was 3 hours and 30 min roughly 1 hour longer than in MIDCAB. The conversion rate to larger incisions was $4.5 \%$ and the revision rate for bleeding was $1.4 \%$. Concerning hard postoperative endpoints a $0.8 \%$ mortality rate, a $0.4 \%$ stroke rate, and a $1.3 \%$ postoperative dialysis rate was noted. Concerning the $1.7 \%$ wound infection rate it needs to be mentioned that port infections are included in this calculation and it cannot be assessed how many deep wound infections at the mini-thoracotomy site occurred.

\section{Comment}

This procedure was popular in the very early phase of minimally invasive coronary bypass grafting, probably because surgeons tried to imitate techniques of laparoscopic and VATS surgery. Videoscopy allows harvesting of the IMA in its full length and enables a direct lateral view on the graft rather than the tangential view that the surgeon faces in MIDCAB. In addition, close ups are possible which enable a detailed view of the graft harvesting process and magnification of IMA side branches. Still the harvesting in the published series took close to $50 \mathrm{~min}$ (data not shown in tables). Vassiliades described a significant dependence of the harvesting time on the patient's body mass index (43). Another advantage of endoscopic support is the fact that the pericardium can be opened under scope vision and so the target vessel can be identified and marked easily. This way placement of the mini-thoracotomy is more precise than in MIDCAB. Probably due to the involvement of video technology and corresponding logistics of installation by the team total operative times are 1 hour longer than described for the latter procedures.

The Emory-Group acquired the largest experience but according to a paper in 2009 has switched from thoracoscopic harvesting to robotic harvesting of the internal mammary arteries in their endo-ACAB operations (45). One challenge might be the $2 \mathrm{D}$ videoscopic vision for the delicate process of IMA harvesting as we know from various other procedures. The hand-eye coordination might be limited initially and requires an individual learning curve to get adapted. It remains to be seen whether the offering of commercially available $3 \mathrm{D}$ videoscopy by industry can lead to revival of this version of minimally invasive CABG.

Revision for bleeding, stroke rates, renal failure rates, and perioperative mortality were very acceptable in the published series. Hospital stay with an average of 5.5 days was similar to the one reported for MIDCAB. Only two papers report intermediate term results $(23,43)$. According 


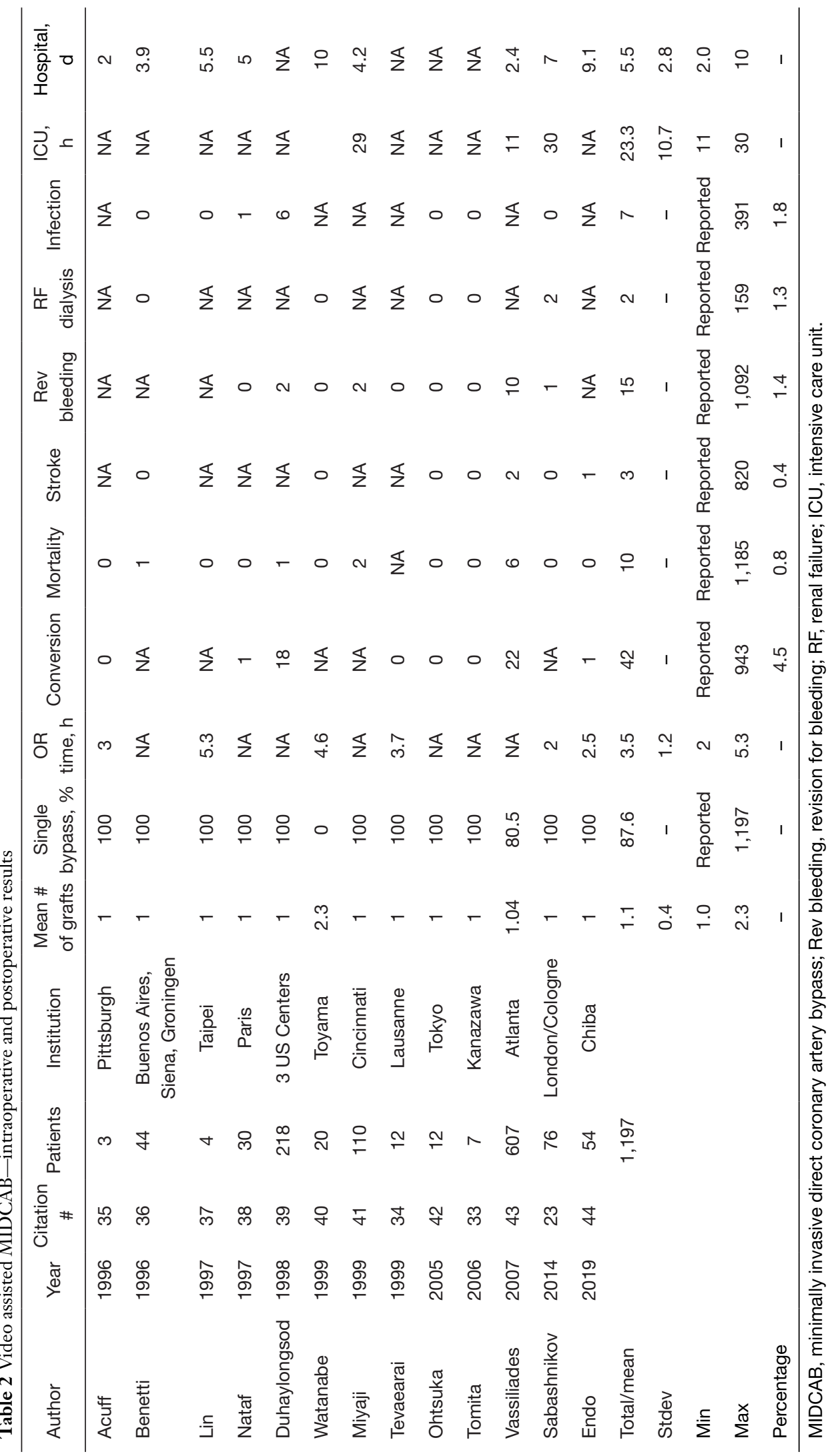


to those a $92 \% 5$-year survival rate was achieved.

In our view the video-assisted MIDCAB procedure was an important and necessary step in the evolution of minimally invasive CABG as it significantly enhanced visualization during graft harvesting and better localization of the target vessels. IMA harvesting is also ergonomically more attractive than under direct vision through a minithoracotomy. One drawback is dependence on an assistant for guidance of the camera. This can be overcome by camera-holding arms but as harvesting affects the whole cranio-caudal length of the chest frequent repositioning is still necessary.

We continue with a view on the role of the heart-lung machine and cardioplegia in minimally invasive CABG.

\section{Coronary bypass grafting on pump with cardioplegia through mini-thoracotomy [PA-CABG, Dresden technique, total coronary revascularization via anterior thoracotomy (TCRAT)]}

\section{Definition}

Surgeons who want to perform coronary bypass grafting through a limited incision but maintain the safety net of the heart lung machine and work on a completely still heart utilize this method. Cardiopulmonary bypass is usually installed in the groin, the ascending aorta is occluded by and endoballoon or via aortic crossclamping. Anastomotic suturing is carried out through the mini-thoracotomy.

\section{Terminology}

The following abbreviations are used and published in the literature: PA-CABG, Dresden technique and TCRAT.

\section{Surgical technique}

The IMA is harvested through the mini-thoracotomy. The groin vessels are usually exposed and remote access cardiopulmonary bypass is installed. In the PA-CABG method a balloon catheter is brought into the side arm of the femoral arterial perfusion cannula and advanced into the aortic root under transesophageal echocardiography (TEE) guidance. Availabity of an anesthesiologist well experienced in TEE is of utmost importance. After going on pump, the endoballoon is inflated and cardioplegia is delivered through the balloon catheter into the aortic root. Ruling out aortoiliac atherosclerosis and ascending aortic pathology preoperatively is extremely important and mandatory when applying the endoballoon together with femoral access perfusion. Surgeons use regular non-thoracoscopic instrumentation for the anastomoses.

The Dresden technique used direct aortic arterial cannulation and direct aortic crossclamping through the mini-thoracotomy (46). Babliak and coworkers from Kiew recently published their method in which a transthoracic Chitwood clamp is inserted instead. All anastomoses are carried out under direct vision through the minithoracotomy (47). As shown by the Kiew group special slings can be placed around the pulmonary veins and also around the inferior vena cava for exposure of the lateral and back wall of the heart.

\section{Results}

Table 3 lists the results of the on pump and cardioplegia versions of minimally invasive CABG (46-51). Eight hundred and ninety-six cases are published in the current literature. An average of two grafts was placed, the rate of single coronary bypass grafting is only $40 \%$. Direct vision LIMA harvesting took an average of $46 \pm 4.2 \mathrm{~min}$ (data not shown in table) and an OR time of 4 hours and $12 \mathrm{~min}$ is reported. The cumulative conversion rate to a larger thoracic incision in a limited number of papers was $0.7 \%$ and the revision rate for bleeding was $2.3 \%$. Mortality in the published series was $0.7 \%$ and the stroke rate reached $1.4 \%$. Average intensive care unit (ICU) stay and hospital stay are reported as $36.4 \mathrm{~h}$ and 5.8 days respectively. Only one paper reports on intermediate term results: Farhat and coworkers noted a 92\% 5-year survival (51).

\section{Comment}

On pump coronary bypass grafting through minithoracotomy was popular during the early stages of less invasive heart surgery in the mid to late 1990s. As compared to beating heart versions more grafts could be placed and overall mortality was slightly lower than in MIDCAB series published during that time. The stroke rate, however, was always higher. This and the fact that retrograde aortic dissections have occurred when the endoballoon technology was introduced (48) have led to criticism about this method. Also cost for the Heartport ${ }^{\mathrm{TM}}$ system was an issue. In addition, enabling technology for beating heart coronary bypass surgery through minithoracotomy developed well and MIDCAB or MICSCABG became the preferred method by many less invasive surgeons. The activities of Babliak and co-workers (47) have caught recent attention and it can be expected that due to his excellent results some groups will take over the method. The endoballoon technology has also undergone 


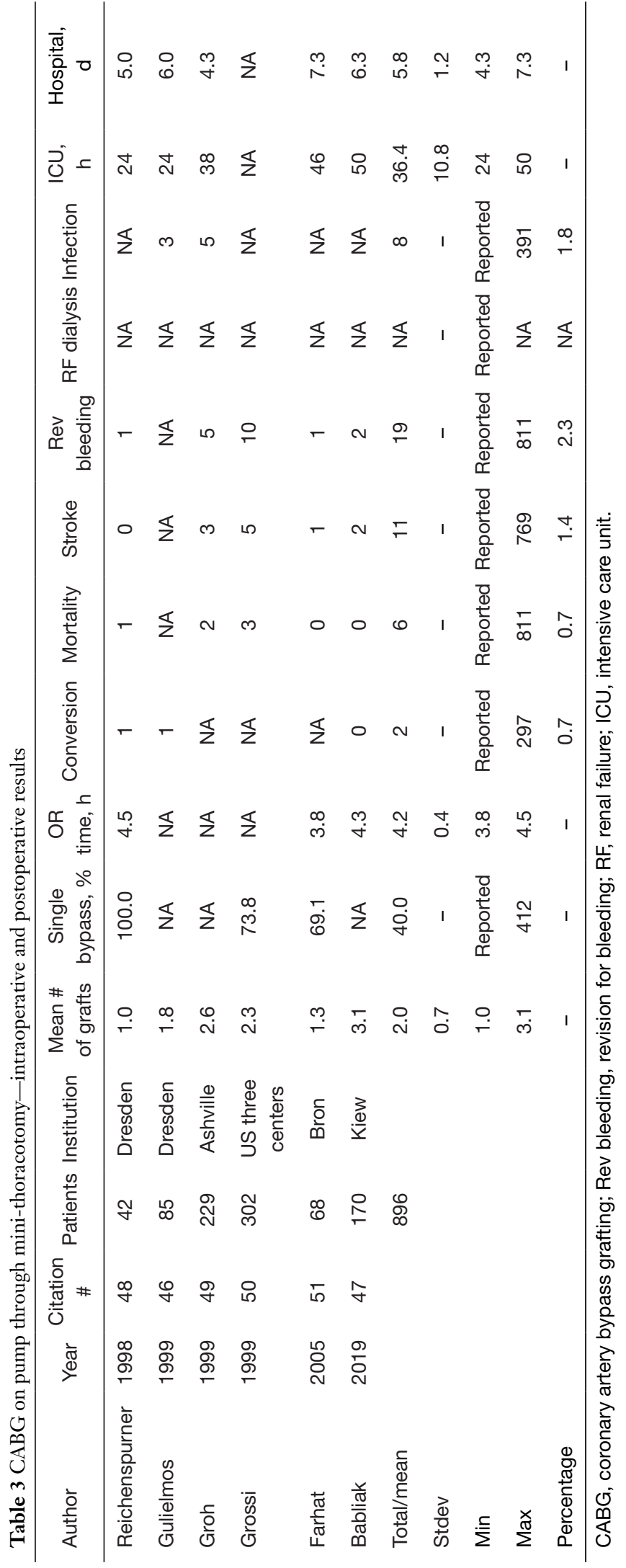

several improvement steps and has become routine at a considerable number of centers. It is, however, used more frequently in the field of minimally invasive mitral valve surgery. For all on pump methods it cannot be overemphasized enough that preoperative imaging of the aortoiliac tree by CT angiography is of utmost importance so as to avoid the catastrophic complication of a retrograde aortic dissection. In the experience of the first author of this review approximately $70 \%$ to $80 \%$ of the CABG population has only mild aortoiliac atherosclerosis and is therefore probably well suited for this procedure. The most striking advantage of on pump minimally invasive CABG is unloading of the heart and therefore a better exposure of the lateral and back wall of the heart as well as a completely still operating field in a limited surgical environment. This makes placement of multiple grafts easier than on the beating heart.

The $4 \mathrm{~h}+$ operative time in the on pump/cardioplegia methods can probably be explained by the more timeconsuming delicate maneuvers of peripheral arterial cannulation and use of the heart lung machine overall. In addition, more bypasses were placed than in MIDCAB and in video assisted MIDCAB.

The next part in this review will deal with the introduction of robotic technology into the field of minimally invasive coronary bypass surgery.

Robotically assisted coronary bypass grafting through minithoracotomy [RACAB, robotically assisted direct coronary artery bypass (RADCAB), robotically assisted MIDCAB]

\section{Definition}

In this version of less invasive coronary bypass surgery the internal mammary arteries are harvested using robotic technology. The graft to coronary anastomoses are performed through a left sided mini-thoracotomy as described for MIDCAB.

\section{Terminology}

Most commonly the terms RACAB, and robotically assisted MIDCAB or robotically assisted endo ACAB are used. One surgeon created the term "precision incision" for this procedure (52).

\section{Surgical technique}

The patient is placed in supine position with the left chest slightly elevated. A double lumen endotracheal tube is introduced and the left lung is deflated. Under left lung 
collapse a camera port is placed into the $4^{\text {th }}$ intercostal space on the anterior axillary line. Instrument ports are placed in the second and $6^{\text {th }}$ intercostal spaces close to the midclavicular line. Insertion of these ports should always be carried out under camera vision. The ports are docked to the arms of a surgical robot. For IMA harvesting a camera view 30 degrees up is taken. A robotic electrocautery spatula is inserted into the right and a robotic forceps is inserted into the left instrument port. The surgeon controls these instruments from a console using joy sticks, so called "masters". He or she looks into a 3D/HD binocular, steers the camera remotely, and activates the electrocautery from the console using a foot pedal. The internal mammary arteries can be harvested in pedicled or skeletonized fashion. Care needs to be taken to use low cautery power, specifically if skeletonized harvesting is chosen. After graft harvesting the pericardial fatpad is taken down and the pericardium is opened using the surgical robot. With the robotic camera the landing zone on the target vessels can be identified and the corresponding appropriate incision site for the minithoracotomy can be chosen. The latter three maneuvers are carried out with a camera view 30 degrees down. The minithoracotomy incision is placed and the rest of the procedure is similar to what has been described above for MIDCAB.

\section{Results}

One thousand seven hundred and sixty-two cases in 12 papers are available in the published literature (23,24,53-62) (Table 4). Mostly single LIMA to LAD bypasses were performed (85.5\% single vessel revascularization). LIMA harvesting times were $57.0 \pm 35.4$ on average (data not shown in the table). Total operative time was $4 \mathrm{~h}$ and the conversion rate to a larger thoracic incision was $6.6 \%$. Revision for bleeding, Mortality and stroke rate are reported as $0.4 \%$ each. Hospital stay was $5.4 \pm 1.6$ days. Five-year survival was calculated in one paper and reached $94 \%$ (44).

\section{Comment}

Robotic assistance has added better visualization, better camera control, 3D vision, magnification, and better surgical dexterity to the field of minimally invasive CABG. This enables a much more comfortable IMA harvesting process. More comfortable bilateral IMA harvesting may also be underlined by the fact that two studies $(56,59)$ found exactly the same harvesting times for the LIMA and the RIMA. The group of Bob Kiaii from London, Ontario recently reported on a series of more than 600 patients with a mortality rate of only $0.3 \%(61)$. In the robotic heart surgery community this procedure has gained more acceptance than the totally endoscopic version most likely because the anastomotic process through a minithoracotomy is more straight forward and can be carried out using classic surgical instrumentation.

Next, we give insights why completely endoscopic coronary bypass grafting using conventional, long-shafted thoracoscopic instrumentation is extremely difficult and explain why technological support by robotic devices is necessary.

\section{Video assisted (non-robotic) totally endoscopic CABG (nrTECAB)}

\section{Definition}

In this procedure IMA harvesting, pericardiotomy, and the anastomoses are all carried out with long shafted minimally invasive instrumentation under videoscopic guidance.

\section{Terminology}

The operation is called as nrTECAB in the literature.

\section{Technique}

Any totally endoscopic surgery is performed through ports only without auxiliary incisions. Therefore, surgeons who developed this procedure placed ports in approximately the same locations as described for robotically assisted MIDCAB and inserted regular thoracoscopic instruments. All procedure steps-IMA takedown, pericardial fatpad removal, opening of the pericardium, and anastomotic suturing were carried out this way.

\section{Results}

Two very small series (31 patients total) are published in the literature $(63,64)$ (Table 5), one from Ulm/Germany another form Kanazwa/Japan $(33,65)$. Both groups managed to perform this extremely difficult operation. The technical challenges are reflected by a $45.1 \%$ conversion rate to larger incisions. There were, however, no mortality events and no strokes occurred. Unfortunately, except for LIMA harvesting (mean $77 \pm 33.9 \mathrm{~min}$ ) no operative times and no detailed further postoperative morbidity are reported in these papers. Longterm data are also unavailable.

\section{Comment}

A nrTECAB approach has been attempted immediately after the advent of remote access heart lung machine perfusion and the endoballoon for endoaortic occlusion 


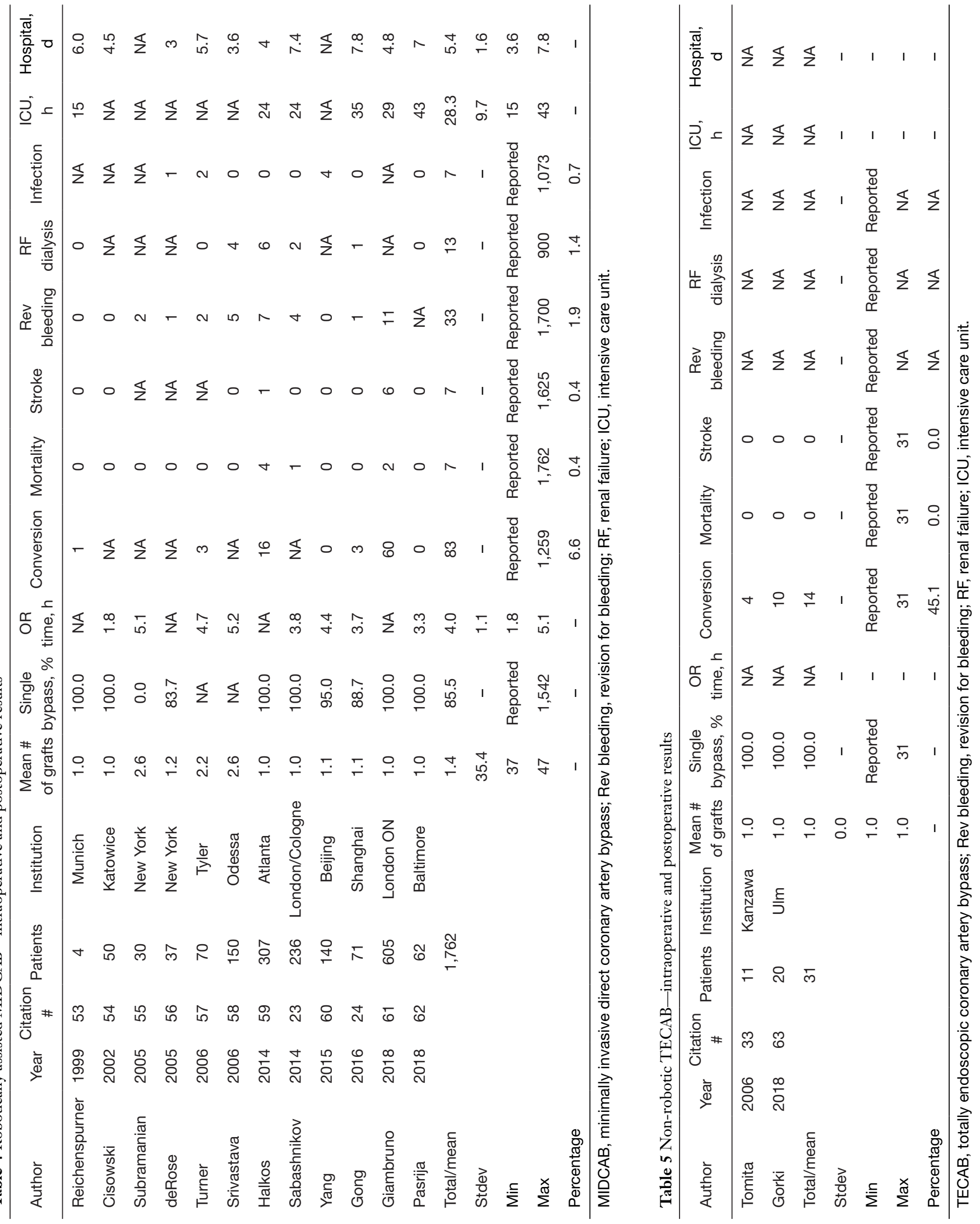




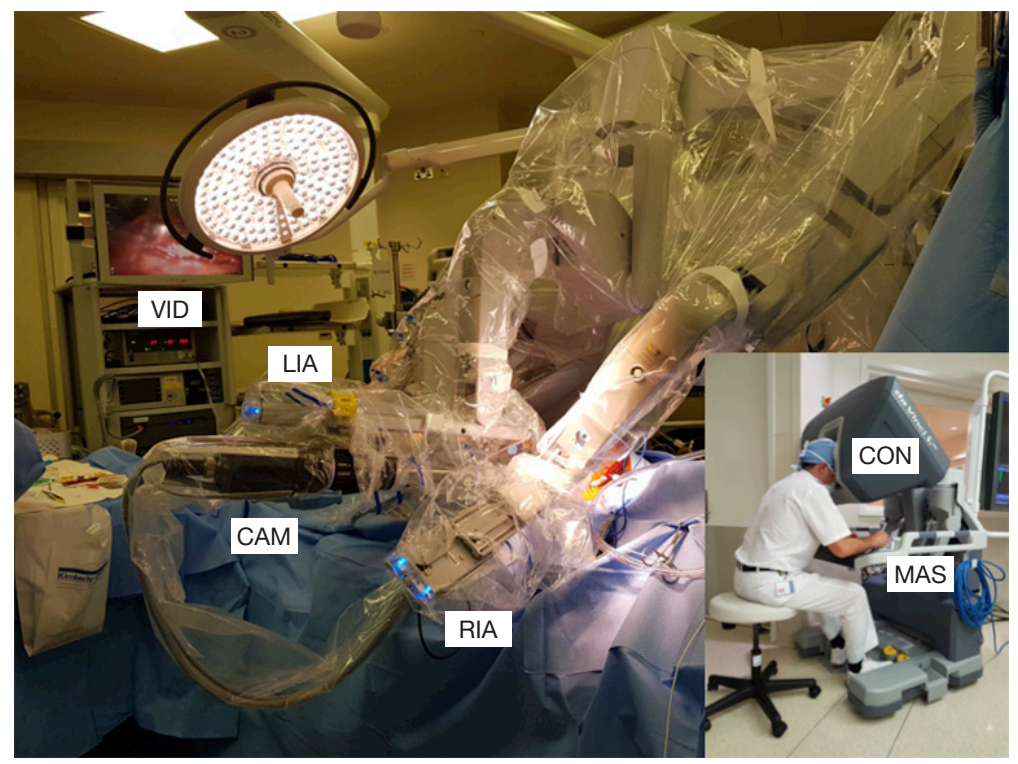

Figure 3 Intraoperative setup in a robotic TECAB procedure. A camera arm (CAM) and a left instrument arm (LIA) and a right instrument arm (RIA) are docked to the patient's left chest. The surgeon controls these arms from a console (CON) using joysticks, so called "masters" (MAS). The surgical team can follow the procedure on a video screen (VID). TECAB, totally endoscopic coronary artery bypass.

and cardioplegia. The Stanford group carried out animal experiments (63). Clinical application by this group was mentioned in talks and discussions but to our knowledge the experience has not been published. Probably due to the extreme technical challenges robotic support was then used to further develop a totally endoscopic version of coronary bypass grafting. Given the technical difficulties it has to be appreciated that two groups attempted the approach clinically. As reflected in the numbers of patients reported and as seen in clinical practice broader application can probably not be expected.

The attempts to perform TECAB using video-assisted thoracoscopic surgery (VATS) instrumentation can almost be regarded as heroic. It is obvious that major technological support is necessary for completely endoscopic suturing of a coronary bypass graft anastomosis. Surgical robots serve this purpose.

\section{Robotically assisted TECAB}

\section{Definition}

In the robotically assisted totally endoscopic method the whole bypass grafting procedure including IMA harvesting, pericardiotomy, and anastomotic suturing is carried out using a surgical robot.

\section{Terminology}

This procedure carries the abbreviation robotic TECAB.

\section{Technique}

Robot docking, IMA harvesting and pericardial opening is performed as described for robotically assisted MIDCAB. Then the target vessel is either immobilized using a robotic suction endostabilizer or the heart is arrested using remote access perfusion and endoballoon cardioplegia (see also PA-CABG). The graft is sutured to the anastomosis with a double armed $7 \mathrm{~cm}$ short $7 / 0$ synthetic suture or anastomosed with an automated anastomotic connector (64). Figure 3 shows the intraoperative setup in a robotic TECAB procedure.

\section{Results}

Since the first robotic TECAB procedure carried out by Loulmet and coworkers in Paris in 1998 (66), 1,678 cases have been published in larger series in the cardiac surgery literature $(21,60,64,66-76)$ (Table 6). The mean graft number is currently $1.2 \pm 0.3$ and multivessel procedures have been increasingly carried out since the mid-2000s. Twenty-seven point eight percent of these procedures were multivessel coronary bypass grafting. Detailed literature on this multivessel approach is available (77). 





Conduit harvesting times amount to $55 \pm 19 \mathrm{~min}$ for LIMA harvesting and 32 min for RIMA harvesting (one single paper reporting on the RIMA) (74). Total operative times reached $5.3 \pm 0.8$ hours and the cumulative conversion rate to a larger thoracic incision for all published TECABs was $10.3 \%$. Revision for bleeding was $3.4 \%$, the stroke rate was $1.0 \%$, and the perioperative mortality reached $1.3 \%$. A $5.2 \pm 1.6$ days hospital stay was reported. Three-year survival is reported by two papers $(21,76)$ at $96 \%$ and $95.5 \%$.

\section{Comment}

Given the more or less complete failure of conventional videoscopic surgery in the attempt to carry out a TECAB procedure robotics proved to be an essential enabling technology. Until now no other technology has provided enough support for a TECAB operation. After an initial phase where only single grafts were carried out bilateral IMA grafting was increasingly performed. Triple and quadruple bypass grafting has been reported (78). Both beating heart and arrested heart versions of robotic TECAB were executed in routine clinical practice by active groups. Despite adequate clinical results overall acceptance in the cardiac surgery community has been slow, most probably due to significant learning curves, long procedure times, significant team commitment, and cost. Concerning learning curves similar to the MIDCAB procedure a triple digit number of repetitions is necessary for the individual surgeon and the team to achieve a good comfort level $(79,80)$. For conversion a learning curve for the whole community of robotic heart surgeons has been described recently (81). Conversion rates affected almost one out of two patients in the early 2000s but nicely fell below $5 \%$ over the last years. Of all minimally invasive coronary bypass grafting procedures robotic TECAB is the most complex with the highest technological demands. From a pure surgical invasiveness perspective, however, it is the coronary surgery procedure with the least tissue trauma. The significant investment in robot hardware, the long training of surgeons and their teams, and also the strong dependence on complex technology and interdependence of all members of the surgical team remains a point of lively discussion. Proper device handling and team training as well as aspects of new surgical robots coming into the field have been described by our group recently (82).

\section{Mixed series}

Two papers in our review did not describe one of the above methods specifically but a mix of different methods $(83,84)$. Results of 345 cases are shown in Table 7. They are in line with what was shown for the individual procedures with a low mortality of $0.6 \%$, a zero percent stroke rate, and hospital stay of only 4.4 days. A 5 -year cumulative survival rate of $95 \%$ is reported by both papers.

\section{Grand total view on minimally invasive and robotic coronary bypass surgery-what can the different approaches offer?}

The first classic coronary bypass grafting procedures through median sternotomy were introduced by Favaloro in 1968 (85) and soon became a worldwide spread and frequently applied procedure (86). It took a little more than 25 years until the idea of reducing the surgical trauma came up. Surgeons in South America had in the early 1980s tried to take out the factor heart lung machine and thereby were successful in reducing blood transfusions and other perioperative adverse events (1). After video assisted thoracic surgery was established Benetti was the first to approach the placement of a LIMA bypass to the LAD through a mini-thoracotomy (2). The chronological development of minimally invasive CABG since then is outlined in Figure 4. The main steps were the availability of videoscopic tools and instruments which allowed working through small incisions and ports, the introduction of suction and pressure stabilizers for beating heart coronary surgery, the invention of surgical robots with multiwristed endeffectors, the availability of anastomotic connector devices, and 3D endoscopy.

\section{Demographics}

Demographics were very inconsistently reported in the literature that we reviewed. The mean age was 61.9 years and $76.5 \%$ of the patients were male (data not shown in tables).

\section{Intraoperative outcome in minimally invasive CABG}

\section{Extent of surgical revascularization}

Table 8 shows the intraoperative and postoperative performance of all methods described in this review. The approaches with the highest degree of surgical revascularization appear to be those which use the heart lung machine. The mean number of grafts placed in these operations was 2.0 and $60 \%$ of the patients received 




multiple bypass grafts. Complete unloading of the heart allows access to all coronary territories including the right coronary artery system and distal branches of the circumflex coronary artery.

\section{Operative times}

LIMA takedown during the 25 years of development was performed in $52.1 \mathrm{~min}$ whereas RIMA harvesting was carried out within $39.7 \mathrm{~min}$ (results not shown in Table 8). Little data is available on harvesting times for the IMA in CABG through median sternotomy. Kieser and coworkers achieved a reduction of harvesting times from 36 to 15 min using the harmonic scalpel (87). The fact that RIMA harvesting in our cumulative analysis was shorter than LIMA harvesting may be explained by the fact that more experienced surgeons harvested the RIMA in multivessel bypass grafting. These surgeons had probably passed the learning curve for LIMA harvesting and managed to take the RIMA down approximately $10 \mathrm{~min}$ faster. Taggart in the ART trial found that adding the RIMA as a second arterial graft added 23 min of operative time (88).

Total operative times for minimally invasive CABG procedures in our review averaged $3 \mathrm{~h}$ and $42 \mathrm{~min}$. Mohr and coworkers in a publication on the SYNTAX trial reported an operative time of 3 hours and $30 \mathrm{~min}$ for patients with an average of 3.4 grafts placed through sternotomy (89). The operative time in the minimally invasively treated patients in our current review was 3 hours 43 min, about a quarter of an hour longer. The mean number of grafts, however was only 1.3 and only $18.5 \%$ of treated patients received two or more bypass grafts. Three hours $50 \mathrm{~min}$ is also a significant prolongation of operative time as compared to the 2 hours $17 \mathrm{~min}$ operative time for $\mathrm{CABG} \times 1$ through sternotomy described by Halkos in 2012 (45). The question remains whether investing longer surgical time for less grafts and reduced surgical trauma is worthwhile. The authors feel that given the overall very promising results it is absolutely justified to further promote CABG through limited incisions. What our review also shows is that the more technology is brought in (videoscopy, heart lung machine, surgical robot) and the more grafts are placed the more extensive operative times get. The limits how long one can allow a minimally invasive coronary bypass grafting procedure to take is not quite clear. An analysis on operative times in robotic TECAB by Wiedemann demonstrated a time frame of approximately $8 \mathrm{~h}$ before morbidity and mortality increase significantly (90). Again, it needs to be kept in mind that operative time in less 


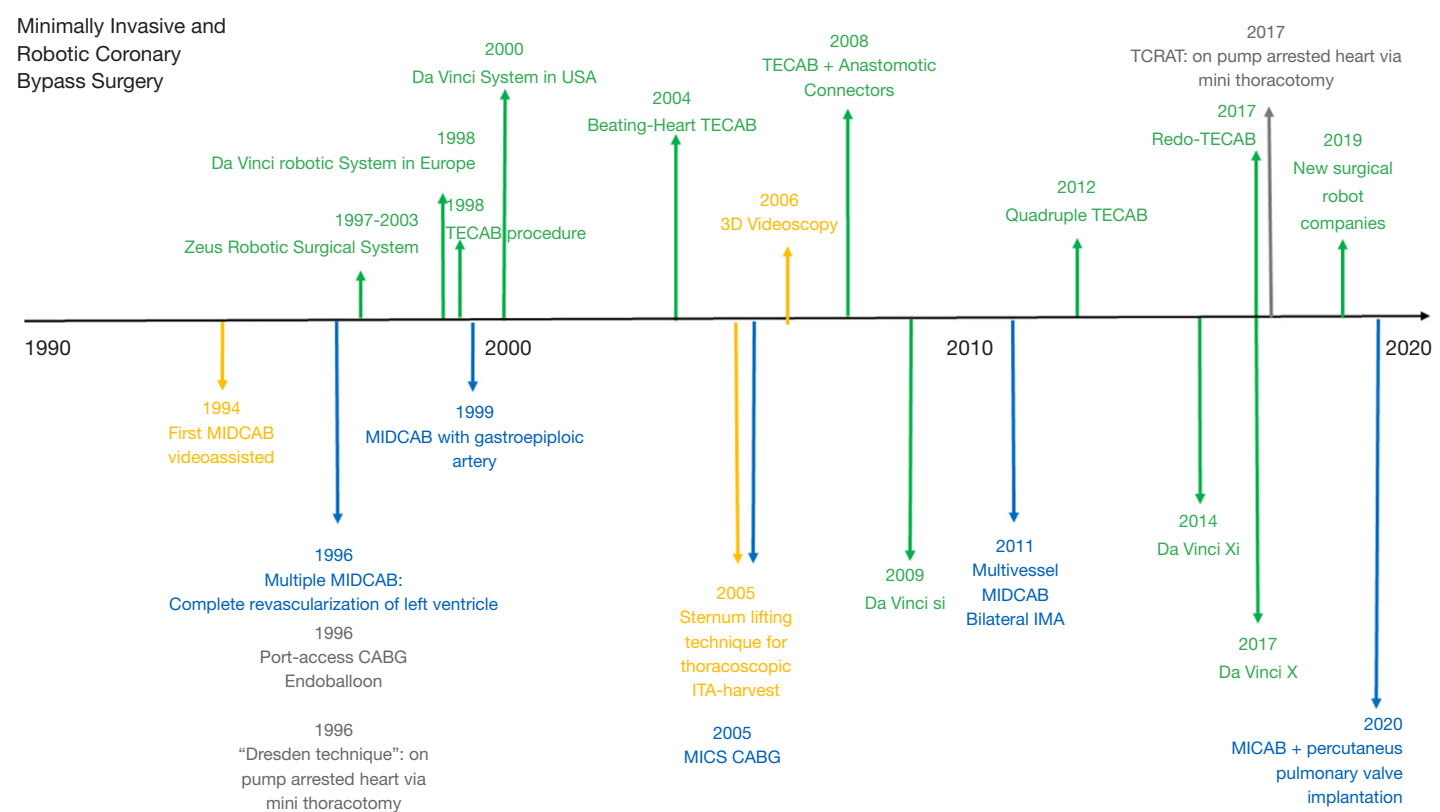

Figure 4 Historical development of minimally invasive coronary bypass surgery. MIDCAB, minimally invasive direct coronary artery bypass; MICS-CABG, minimally invasive cardiac surgery-coronary artery bypass grafting; TECAB, totally endoscopic coronary artery bypass; IMA, internal mammary artery; MICAB, minimally invasive coronary artery bypass.

Table 8 Grand total minimally invasive CABG-intraoperative and postoperative results



CABG, coronary artery bypass grafting; Rev bleeding, revision for bleeding; RF, renal failure; ICU, intensive care unit. 
invasive $\mathrm{CABG}$ means increased surgical time with reduced trauma and a burden to the thoracic tissue lower than in median sternotomy approaches. We suggest that this delicate balance deserves more investigation.

\section{Conversion to larger thoracic incisions}

Conversion to larger incisions in case of technical difficulties has been a known fact in less invasive surgery practiced in other disciplines and also was part of less invasive coronary bypass grafting from the very beginning. Our review revealed an overall conversion rate of $4.3 \%$. Conversion should never be seen as failure but as a necessary step and should be carried out liberally if technical problems occur.

\section{Postoperative outcome}

\section{Mortality}

Perioperative mortality rates in pooled large prospective randomized trials are $1.5 \%$ for off-pump coronary bypass grafting and exactly the same (1.5\%) for on pump coronary bypass surgery (91). In 2011 a review of the STS database looking at 101,188 patients undergoing CABG revealed a 30 -day mortality rate of $1.6 \%$ to $5.3 \%$ depending on the use of one, two, or no internal mammary arteries (92). A similar study investigating 144,526 patients in the STS database found a perioperative mortality in the range of $1.7 \%$ to $2.6 \%$ depending on procedural volume (93). From this perspective the $1.0 \%$ total mortality rate in minimally invasive CABG shown in this article appears very satisfactory but needs to be seen with caution as, again, the mean number of grafts placed was 1.3. The mean number of grafts in the SYNTAX trial was 3.5 and Mohr and coworkers report a $0.9 \%$ mortality rate for the selected patients in this large randomized trial (89). Literature on CABG mortality depending on the grade of surgical revascularization (45,94-100) shows a clear trend that rates increase with the number of vessels diseased and the number of grafts placed. The cumulative mortality for conventional single and double coronary bypass and CABG for single and double vessel disease is published in the range of $0 \%$ to $2 \%$ with a mean of $0.9 \%$ for single vessel disease/single bypass and $1.6 \%$ for double vessel disease/double bypass. The corresponding rate for triple vessel disease/triple bypass is $2.9 \%$. It can therefore be stated that minimally invasive procedures clearly maintained the level of perioperative survival which is expected for low complexity conventional CABG through sternotomy and many series of mini-CABG were reported with $0 \%$ mortality despite the presence of innovation and learning curves.

\section{Stroke}

The recent large CABG trial FREEDOM reported a perioperative stroke rate of $1.8 \%$ (101). In the ISMICS consensus statement on sternotomy off-pump versus onpump CABG perioperative stroke rates were $1.4 \%$ and $2.1 \%$ respectively (91). Halkos found a $1.3 \%$ stroke rate in a series of 234 patients undergoing sternotomy CABG for single vessel disease (45). Papers on low complexity CABG show a stroke rate between $0 \%$ and $1.3 \%$ for conventional CABG in single vessel disease or single bypass grafting $(45,98,99)$. A cumulative $0.6 \%$ stroke rate in 25 years of minimally invasive CABG appears therefore very satisfactory and may indicate that less invasive procedures lead to relatively low stroke rates. Attempts to further reduce stroke rates in coronary surgery are extremely important in the competition with catheter-based intervention which is superior to coronary surgery from this aspect in most studies.

\section{Revision for bleeding}

Puskas in the large ISMICS meta-analysis and consensus statement on off-pump versus on-pump CABG which investigated 19,101 patients in 102 randomized trials reported a revision rate for bleeding of $2.3 \%$ and $2.6 \%$ respectively (91). We found a cumulative rate of revision for bleeding of $2.5 \%$ in minimally invasive CABG. The highest rates were noted for MIDCAB and robotic TECAB. Why minimally invasive approaches failed to reduce bleeding rates needs further evaluation. Factors that may have played a role are innovation and learning curves, surgical technical difficulties and extensive operative times.

\section{Renal failure, dialysis}

Our literature review revealed a renal failure rate exactly in the range of what the Emory group reported for patients who underwent sternotomy single CABG $(0.9 \%)(45)$. Definitions of renal failure, however, were not standardized in the papers we reviewed and the hard endpoints mortality, stroke, and revision for bleeding were much more consequently reported. Renal failure is also very dependent on postoperative treatment on the ICU.

\section{Wound infection}

In larger CABG series we see rates of sternal wound infection in the range of $2.4 \%$ to $4.4 \%$ (91). The wound infection rate of $1.2 \%$ in our analysis from this perspective appears more than acceptable. On the other hand, 
Halkos and coworkers described a $0.4 \%$ deep wound infection rate for patients undergoing conventional single CABG procedures (45). We have to keep in mind that wound infections in minimally invasive surgery are many times confined to the mini-thoracotomy area or may be in relation with infected ports in TECAB, a pattern completely different from deep sternal wound infection and mediastinitis. The variable sternal osteomyelitis is largely taken out of the equation. Potential risk factors that are not seen in sternotomy CABG are long periods of spreading a small incision and long periods of ports moving in an intercostal space for hours. Both mechanisms can lead to local tissue necrosis and bacterial contamination with subsequent local infection that may spread into the chest. The likelihood of reaching deep compartments is probably lower. If bilateral IMAs are used a sternal sparing approach appears specifically attractive. Taggart noted a $1.9 \%$ sternal wound complication rate if single IMA is used in sternotomy CABG in the ART trial. The rate was 3.5\% for double IMA (88). Minimally invasive, sternal sparing methods can probably help to overcome this risk associated with bilateral IMA use, an advantage that should be specifically attractive for insulin dependent diabetics, obese patients, and those with COPD.

\section{Hospital stay}

Despite the fact that some perioperative adverse events seen in minimally invasive CABG are not reduced as compared with sternotomy CABG an average hospital stay of 5.6 days is encouraging but does not quite fulfill the promises of less invasive heart surgery to reduce length of stay dramatically. The large SYNTAX trial reported a postoperative stay of 9.0 days after multivessel sternotomy CABG (89), in the ISMICS off-pump versus on-pump CABG consensus statement hospital stay was 7.6 days and 8.4 days respectively (91). Halkos found a 5.8-day postoperative length of stay in 234 patients undergoing sternotomy CABG for single vessel disease and showed a gain of 0.6 days if non-sternotomy methods were applied (45). A mean hospital stay of 5.4 days for patients with low complexity single vessel disease/single coronary bypass through sternotomy is reported in the literature $(45,99)$. It needs to be considered that factors related to different health care systems may to some extent influence the length of hospital stay. The effects of a less traumatic version of CABG are probably more visible during the first few weeks postoperatively and more comparative studies looking into the speed of recovery during this phase are warranted.

\section{Conclusions}

From this review looking into 25 years of development in minimally invasive CABG it can be concluded that the vast majority of patients receives single LIMA to LAD bypass grafts and the number of multivessel CABG cases performed through mini-thoracotomy or through ports has increased only recently. Six major groups of surgical approaches can be defined depending on extent of the incision, use of videoscopy, use of the heart lung machine, and application of robotic technology.

The most important and appealing aspect of the method is that the incision length and the overall surgical trauma are significantly reduced. But procedures require longer operative times than reported for open CABG through sternotomy. In more than $95 \%$ of patients the procedures are technically successful with full sternal preservation. The awareness of a potential larger opening of the chest due to technical issues in the rest of patients is important.

The hard-postoperative outcome variables mortality, stroke, and renal failure lie clearly in the $1 \%$ to below $1 \%$ range indicating that procedure development has not compromised basic safety standards of surgical coronary revascularization. For stroke there is a signal that minimally invasive procedures may even result in a rate lower than in open procedures. Revision for bleeding lies in the range of rates reported for sternotomy CABG. The occurrence of renal failure rates is also similar. Wound infection rates seem to be acceptable but wound infection follows a different pattern than in sternotomy. Complete sternal preservation when bilateral IMAs are used is one of the main advantages of minimally invasive CABG. There are reports of patients being sent home as early as 2 or 3 days postoperatively but the average hospital stay after minimally invasive coronary surgery is essentially in line with what is seen after sternotomy for low complexity CABG. Benefits in the early rehabilitation phase are usually not reported in larger series but would deserve deeper evaluation. Five-year survival matches results of open CABG.

Minimally invasive and robotically assisted techniques are in any case important components to make surgical coronary revascularization fit for the $21^{\text {st }}$ century and competitive in the spectrum of treatment methods for coronary artery disease. 


\section{Acknowledgments}

We acknowledge the efforts of all colleagues who have worked on the development of minimally invasive coronary artery bypass grafting.

Funding: None.

\section{Footnote}

Provenance and Peer Review: This article was commissioned by the Guest Editors (Jason Ali and Yasir Abu-Omar) for the series "Minimally Invasive Cardiac Surgery" published in Fournal of Thoracic Disease. The article has undergone external peer review.

Conflicts of Interest: All authors have completed the ICMJE uniform disclosure form (available at http://dx.doi. org/10.21037/jtd-20-1535). The series "Minimally Invasive Cardiac Surgery" was commissioned by the editorial office without any funding or sponsorship. The authors have no other conflicts of interest to declare.

Ethical Statement: The authors are accountable for all aspects of the work in ensuring that questions related to the accuracy or integrity of any part of the work are appropriately investigated and resolved.

Open Access Statement: This is an Open Access article distributed in accordance with the Creative Commons Attribution-NonCommercial-NoDerivs 4.0 International License (CC BY-NC-ND 4.0), which permits the noncommercial replication and distribution of the article with the strict proviso that no changes or edits are made and the original work is properly cited (including links to both the formal publication through the relevant DOI and the license). See: https://creativecommons.org/licenses/by-nc-nd/4.0/.

\section{References}

1. Buffolo E, de Andrade J, Branco J, et al. Coronary artery bypass grafting without cardiopulmonary bypass. Ann Thorac Surg 1996;61:63-6.

2. Benetti FJ. Uso de la toracoscopeia en cirugia coronaria para diseccion de la arteria mamaria interna. Prensa Med Argent 1994;81:877-9.

3. Subramanian VA, McCabe JC, Geller CM. Minimally invasive direct coronary artery bypass grafting: two-year clinical experience. Ann Thorac Surg 1997;64:1648-53; discussion 1654-5.

4. Calafiore AM, Vitolla G, Mazzei V, et al. The LAST operation: techniques and results before and after the stabilization era. Ann Thorac Surg 1998;66:998-1001.

5. Zenati M, Cohen H, Holubkov R, et al. Preoperative risk models for minimally invasive coronary bypass: a preliminary study. J Thorac Cardiovasc Surg 1998;116:584-9.

6. Bonatti J, Ladurner R, Antretter H, et al. Single coronary artery bypass grafting--a comparison between minimally invasive 'off pump' techniques and conventional procedures. Eur J Cardiothorac Surg 1998;14 Suppl 1:S7-12.

7. Repossini A, Moriggia S, Cianci V, et al. The LAST operation is safe and effective: MIDCABG clinical and angiographic evaluation. Ann Thorac Surg 2000;70:74-8.

8. Cremer JT, Wittwer T, Böning A, et al. Minimally invasive coronary artery revascularization on the beating heart. Ann Thorac Surg 2000;69:1787-91.

9. Mehran R, Dangas G, Stamou S, et al. One-year clinical outcome after minimally invasive direct coronary artery bypass. Circulation 2000;102:2799-802.

10. Gersbach P, Imsand C, von Segesser LK, et al. Beating heart coronary artery surgery: is sternotomy a suitable alternative to minimal invasive technique? Eur J Cardiothorac Surg 2001;20:760-4.

11. Drenth DJ, Winter JB, Veeger NJ, et al. Minimally invasive coronary artery bypass grafting versus percutaneous transluminal coronary angioplasty with stenting in isolated high-grade stenosis of the proximal left anterior descending coronary artery: six months' angiographic and clinical follow-up of a prospective randomized study. J Thorac Cardiovasc Surg 2002;124:130-5.

12. Oliveira SA, Lisboa LA, Dallan LA, et al. Minimally invasive single-vessel coronary artery bypass with the internal thoracic artery and early postoperative angiography: midterm results of a prospective study in 120 consecutive patients. Ann Thorac Surg 2002;73:505-10.

13. Vicol C, Nollert G, Mair H, et al. Midterm results of beating heart surgery in 1-vessel disease: minimally invasive direct coronary artery bypass versus off-pump coronary artery bypass with full sternotomy. Heart Surg Forum 2003;6:341-4.

14. Reeves BC, Angelini GD, Bryan AJ, et al. A multi-centre randomised controlled trial of minimally invasive direct coronary bypass grafting versus percutaneous transluminal coronary angioplasty with stenting for proximal stenosis of the left anterior descending coronary artery. Health 
Technol Assess 2004;8:1-43.

15. Shirai K, Lansky A, Mehran R, et al. Minimally invasive coronary artery bypass grafting versus stenting for patients with proximal left anterior descending coronary artery disease. Am J Cardiol 2004;93:959-62.

16. Hong SJ, Lim DS, Seo HS, et al. Percutaneous coronary intervention with drug-eluting stent implantation vs. minimally invasive direct coronary artery bypass (MIDCAB) in patients with left anterior descending coronary artery stenosis. Catheter Cardiovasc Interv 2005;64:75-81.

17. Kim JW, Lim DS, Sun K, et al. Stenting or MIDCAB using ministernotomy for revascularization of proximal left anterior descending artery? Int J Cardiol 2005;99:437-41.

18. Ben-Gal Y, Mohr R, Braunstein R, et al. Revascularization of left anterior descending artery with drug-eluting stents: comparison with minimally invasive direct coronary artery bypass surgery. Ann Thorac Surg 2006;82:2067-71.

19. Holzhey DM, Jacobs S, Mochalski M, et al. Seven-year follow-up after minimally invasive direct coronary artery bypass: experience with more than 1300 patients. Ann Thorac Surg 2007;83:108-14.

20. McGinn JT Jr, Usman S, Lapierre H, et al. Minimally invasive coronary artery bypass grafting: dual-center experience in 450 consecutive patients. Circulation 2009;120:S78-84.

21. Jegaden O, Wautot F, Sassard T, et al. Is there an optimal minimally invasive technique for left anterior descending coronary artery bypass? J Cardiothorac Surg 2011;6:37.

22. Etienne PY, Glineur D, Papadatos S, et al. Comparison of minimally invasive direct coronary artery bypass surgery with implantation of drug-eluting stentsin patients with left anterior descending coronary artery disease. Innovations (Phila) 2009;4:340-4.

23. Sabashnikov A, Patil NP, Weymann A, et al. Outcomes after different non-sternotomy approaches to left singlevessel revascularization: a comparative study with up to 10year follow-up. Eur J Cardiothorac Surg 2014;46:e48-55.

24. Gong W, Cai J, Wang Z, et al. Robot-assisted coronary artery bypass grafting improves shortterm outcomes compared with minimally invasive direct coronary artery bypass grafting. J Thorac Dis 2016;8:459-68.

25. Kikuchi K, Chen X, Mori M, et al. Perioperative outcomes of off-pump minimally invasive coronary artery bypass grafting with bilateral internal thoracic arteries under direct vision. Interact Cardiovasc Thorac Surg 2017;24:696-701.

26. Yang M, Xiao L, Gao Z, et al. Clinical effect and prognosis of off-pump minimally invasive direct coronary artery bypass. Med Sci Monit 2017;23:1123-8.

27. Nambiar P, Kumar S, Mittal C, et al. Minimally invasive coronary artery bypass grafting with bilateral internal thoracic arteries: will this be the future? J Thorac Cardiovasc Surg 2018;155:190-7.

28. Holzhey DM, Jacobs S, Walther T, et al. Cumulative sum failure analysis for eight surgeons performing minimally invasive direct coronary artery bypass. J Thorac Cardiovasc Surg 2007;134:663-9.

29. Lopes NH, Paulitsch Fda S, Gois AF, et al. Impact of number of vessels disease on outcome of patients with stable coronary artery disease: 5 -year follow-up of the Medical, Angioplasty, and bypass Surgery study (MASS). Eur J Cardiothorac Surg 2008;33:349-54.

30. Jaffery $Z$, Kowalski $M$, Weaver W, et al. A meta-analysis of randomized control trials comparing minimally invasive direct coronary bypass grafting versus percutaneous coronary intervention for stenosis of the proximal left anterior descending artery. Eur J Cardiothorac Surg 2007;31:691-7.

31. Deo SV, Sharma V, Shah IK, et al. Minimally invasive direct coronary artery bypass graft surgery or percutaneous coronary intervention for proximal left anterior descending artery stenosis: a meta-analysis. Ann Thorac Surg 2014;97:2056-65.

32. Deppe AC, Liakopoulos OJ, Kuhn EW, et al. Minimally invasive direct coronary bypass grafting versus percutaneous coronary intervention for singlevessel disease: a meta-analysis of 2885 patients. Eur J Cardiothorac Surg 2015;47:397-406; discussion 406.

33. Tomita S, Watanabe G, Tabata S, et al. Total endoscopic beating-heart coronary artery bypass grafting using a new 3D imaging system. Innovations (Phila) 2006;1:243-6.

34. Tevaearai HT, Mueller XM, Stumpe F, et al. Advantages of a modified gastroscope for video-assisted internal mammary artery harvesting. Ann Thorac Surg 1999;67:872-3.

35. Acuff TE, Landreneau RJ, Griffith BP, et al. Minimally invasive coronary artery bypass grafting. Ann Thorac Surg 1996;61:135-7.

36. Benetti F, Mariani MA, Sani G, et al. Video-assisted minimally invasive coronary operations without cardiopulmonary bypass: a multicenter study. J Thorac Cardiovasc Surg 1996;112:1478-84.

37. Lin PJ, Chang CH, Chu JJ, et al. Video-assisted coronary artery bypass grafting during hypothermic fibrillatory arrest. Ann Thorac Surg 1997;63:1113-7. 
38. Nataf P, Lima L, Benarim S, et al. Video-assisted coronary bypass surgery: clinical results. Eur J Cardiothorac Surg 1997;11:865-9.

39. Duhaylongsod FG, Mayfield WR, Wolf RK.

Thoracoscopic harvest of the internal thoracic artery: a multicenter experience in 218 cases. Ann Thorac Surg 1998;66:1012-7.

40. Watanabe G, Misaki T, Kotoh K, et al. Multiple minimally invasive direct coronary artery bypass grafting for the complete revascularization of the left ventricle. Ann Thorac Surg 1999;68:131-6.

41. Miyaji K, Wolf R, Flege J, et al. Surgical results of videoassisted minimally invasive direct coronary artery bypass. Ann Thorac Surg 1999;67:1018-21.

42. Ohtsuka T, Ninomiya M, Maemura T. Sternum lifting technique for thoracoscopic internal thoracic artery harvest. Eur J Cardiothorac Surg 2005;27:1119-21.

43. Vassiliades TA Jr, Reddy VS, Puskas JD, et al. Longterm results of the endoscopic atraumatic coronary artery bypass. Ann Thorac Surg 2007;83:979-84; discussion 984-5.

44. Endo Y, Nakamura Y, Kuroda M, et al. The utility of a 3d endoscope and robot-assisted system for MIDCAB. Ann Thorac Cardiovasc Surg 2019;25:200-4.

45. Halkos ME, Vassiliades TA, Myung RJ, et al. Sternotomy versus nonsternotomy LIMA-LAD grafting for singlevessel disease. Ann Thorac Surg 2012;94:1469-77.

46. Gulielmos V, Brandt M, Knaut M, et al. The Dresden approach for complete multivessel revascularization. Ann Thorac Surg 1999;68:1502-5.

47. Babliak O, Demianenko V, Melnyk Y, et al. Complete coronary revascularization via left anterior thoracotomy. Innovations (Phila) 2019;14:330-41.

48. Reichenspurner H, Gulielmos V, Wunderlich J, et al. Port-access coronary artery bypass grafting with the use of cardiopulmonary bypass and cardioplegic arrest. Ann Thorac Surg 1998;65:413-9.

49. Groh MA, Sutherland SE, Burton HG 3rd, et al. Portaccess coronary artery bypass grafting: technique and comparative results. Ann Thorac Surg 1999;68:1506-8.

50. Grossi EA, Groh MA, Lefrak EA, et al. Results of a prospective multicenter study on port-access coronary bypass grafting. Ann Thorac Surg 1999;68:1475-7.

51. Farhat F, Vergnat M, Blanc P, et al. Which place for Port Access TM surgery in coronary artery bypass grafting? A mid-term follow up study. Interact Cardiovasc Thorac Surg 2006;5:71-4.

52. Sutter FP, Berry T, Wertan MC. Precision incision: robotic coronary revascularization via 3.9-cm minithoracotomy. Innovations (Phila) 2012;7:223-8.

53. Reichenspurner H, Boehm D, Gulbins H, et al. Robotically assisted endoscopic coronary artery bypass procedures without cardiopulmonary bypass. J Thorac Cardiovasc Surg 1999;118:960-1.

54. Cisowski M, Drzewiecki J, Drzewiecka-Gerber A, et al. Primary stenting versus MIDCAB: preliminary reportcomparision of two methods of revascularization in single left anterior descending coronary artery stenosis. Ann Thorac Surg 2002;74:S1334-9.

55. Subramanian VA, Patel NU, Patel NC, et al. Robotic assisted multivessel minimally invasive direct coronary artery bypass with port-access stabilization and cardiac positioning: paving the way for outpatient coronary surgery? Ann Thorac Surg 2005;79:1590-6; discussion 1590-6.

56. Derose JJ Jr, Balaram SK, Ro C, et al. Mid-term results and patient perceptions of robotically-assisted coronary artery bypass grafting. Interact Cardiovasc Thorac Surg 2005;4:406-11.

57. Turner WF Jr, Sloan JH. Robotic-assisted coronary artery bypass on a beating heart: initial experience and implications for the future. Ann Thorac Surg 2006;82:7904; discussion 794.

58. Srivastava S, Gadasalli S, Agusala M, et al. Use of bilateral internal thoracic arteries in CABG through lateral thoracotomy with robotic assistance in 150 patients. Ann Thorac Surg 2006;81:800-6.

59. Halkos ME, Liberman HA, Devireddy C, et al. Early clinical and angiographic outcomes after robotic-assisted coronary artery bypass surgery. J Thorac Cardiovasc Surg 2014;147:179-85.

60. Yang $M$, Wu J, Wang G, et al. Robotic total arterial offpump coronary artery bypass grafting: seven-year singlecenter experience and long-term follow-up of graft patency. Ann Thorac Surg 2015;100:1367-73.

61. Giambruno V, Chu MW, Fox S, et al. Robotic-assisted coronary artery bypass surgery: an 18-year single-centre experience. Int J Med Robot 2018;14:e1891.

62. Pasrija C, Kon Z, Ghoreishi M, et al. Cost and outcome of minimally invasive techniques for coronary surgery using robotic technology. Innovations (Phila) 2018;13:282-6.

63. Stevens JH, Burdon TA, Siegel LC, et al. Port-access coronary artery bypass with cardioplegic arrest: acute and chronic canine studies. Ann Thorac Surg 1996;62:435-40; discussion 441.

64. Balkhy HH, Wann LS, Krienbring D, et al. Integrating 
coronary anastomotic connectors and robotics toward a totally endoscopic beating heart approach: review of 120 cases. Ann Thorac Surg 2011;92:821-7.

65. Gorki H, Liu J, Sabau M, et al. Nonrobotic total endoscopic coronary artery bypass grafting a proofof-concept study in 20 patients. Innovations (Phila) 2018;13:344-8.

66. Loulmet D, Carpentier A, d'Attellis N, et al. Endoscopic coronary artery bypass grafting with the aid of robotic assisted instruments. J Thorac Cardiovasc Surg 1999;118:4-10.

67. Boyd WD, Rayman R, Desai ND, et al. Closed-chest coronary artery bypass grafting on the beating heart with the use of a computer-enhanced surgical robotic system. J Thorac Cardiovasc Surg 2000;120:807-9.

68. Loisance DY, Nakashima K, Kirsch M. Computer-assisted coronary surgery: lessons from an initial experience. Interact Cardiovasc Thorac Surg 2005;4:398-401.

69. Argenziano M, Katz M, Bonatti J, et al. Results of the prospective multicenter trial of robotically assisted totally endoscopic coronary artery bypass grafting. Ann Thorac Surg 2006;81:1666-74; discussion 1674-5.

70. de Cannière D, Wimmer-Greinecker G, Cichon R, et al. Feasibility, safety, and efficacy of totally endoscopic coronary artery bypass grafting: multicenter European experience. J Thorac Cardiovasc Surg 2007;134:710-6.

71. Kappert U, Tugtekin S, Cichon R, et al. Robotic totally endoscopic coronary artery bypass: a word of caution implicated by a five-year follow-up. J Thorac Cardiovasc Surg 2008;135:857-62.

72. Folliguet TA, Dibie A, Philippe F, et al. Roboticallyassisted coronary artery bypass grafting. Cardiol Res Pract 2010;2010:175450.

73. Dhawan R, Roberts J, Wroblewski K, et al. Multivessel beating heart robotic myocardial revascularization increases morbidity and mortality. J Thorac Cardiovasc Surg 2012;143:1056-61.

74. Bonaros N, Schachner T, Lehr E, et al. Five hundred cases of robotic totally endoscopic coronary artery bypass grafting: predictors of success and safety. Ann Thorac Surg 2013;95:803-12.

75. Zaouter C, Imbault J, Labrousse L, et al. Association of robotic totally endoscopic coronary artery bypass graft surgery associated with a preliminary cardiac enhanced recovery after surgery program: a retrospective analysis. J Cardiothorac Vasc Anesth 2015;29:1489-97.

76. Balkhy HH, Nisivaco S, Kitahara H, et al. Robotic multivessel endoscopic coronary bypass: impact of a beating-heart approach with connectors. Ann Thorac Surg 2019;108:67-73.

77. Bonatti J, Lee J, Bonaros N, et al. Robotic totally endoscopic multivessel coronary artery bypass grafting. Innovations (Phila) 2012;7:3-8.

78. Bonatti J, Wehman B, de Biasi AR, et al. Totally endoscopic quadruple coronary artery bypass grafting is feasible using robotic technology. Ann Thorac Surg 2012;93:e111-2.

79. Oehlinger A, Bonaros N, Schachner T, et al. Robotic endoscopic left internal mammary artery harvesting: what have we learned after 100 cases? Ann Thorac Surg 2007;83:1030-4.

80. Cheng N, Gao C, Yang M, et al. Analysis of the learning curve for beating heart, totally endoscopic, coronary artery bypass grafting. J Thorac Cardiovasc Surg 2014;148:1832-6.

81. Göbölös L, Ramahi J, Obeso A, et al. Robotic totally endoscopic coronary artery bypass grafting: systematic review of clinical outcomes from the past two decades. Innovations (Phila) 2019;14:5-16.

82. Bonatti J, Wallner S, Winkler B, et al. Robotic totally endoscopic coronary artery bypass grafting: current status and future prospects. Expert Rev Med Devices 2020;17:33-40.

83. Benedetto U, Raja S, Soliman R, et al. Minimally invasive direct coronary artery bypass improves late survival compared with drug-eluting stents in isolated proximal left anterior descending artery disease: a 10-year followup, single-center, propensity score analysis. J Thorac Cardiovasc Surg 2014;148:1316-22.

84. Smith NJ, Miles B, Cain MT, et al. Minimally invasive single-vessel left internal mammary to left anterior descending artery bypass grafting improves outcomes over conventional sternotomy: a single-institution retrospective cohort study. J Card Surg 2019;34:788-95.

85. Favaloro RG. Saphenous vein autograft replacement of severe segmental coronary artery occlusion: operative technique. Ann Thorac Surg 1968;5:334-9.

86. Loop FD. Coronary artery surgery. Ann Thorac Surg 2005;79:S2221-7.

87. Kieser TM, Rose MS, Aluthman U, et al. Quicker yet safe: skeletonization of 1640 internal mammary arteries with harmonic technology in 965 patients. Eur J Cardiothorac Surg 2014;45:e142-50.

88. Taggart DP, Altman DG, Gray AM, et al. Randomized trial to compare bilateral vs. Single internal mammary coronary artery bypass grafting: 1-year results of the 
Arterial Revascularisation Trial (ART). Eur Heart J 2010;31:2470-81.

89. Mohr FW, Rastan AJ, Serruys PW, et al. Complex coronary anatomy in coronary artery bypass graft surgery: impact of complex coronary anatomy in modern bypass surgery? Lessons learned from the SYNTAX trial after two years. J Thorac Cardiovasc Surg 2011;141:130-40.

90. Wiedemann D, Bonaros N, Schachner T, et al. Surgical problems and complex procedures: issues for operative time in robotic totally endoscopic coronary artery bypass grafting. J Thorac Cardiovasc Surg 2012;143:639-47.e2.

91. Puskas JD, Martin J, Cheng DC, et al. ISMICS consensus conference and statements of randomized controlled trials of off-pump versus conventional coronary artery bypass surgery. Innovations (Phila) 2015;10:219-29.

92. Jacobs JP, Edwards FH, Shahian DM, et al. Successful linking of the Society of Thoracic Surgeons database to social security data to examine survival after cardiac operations. Ann Thorac Surg 2011;92:32-7; discussion 38-9.

93. Shahian DM, O'Brien SM, Normand SL, et al. Association of hospital coronary artery bypass volume with processes of care, mortality, morbidity, and the Society of Thoracic Surgeons composite quality score. J Thorac Cardiovasc Surg 2010;139:273-82.

94. Bricker DL, Dalton ML Jr. Cardiac surgery in the community hospital. Ann Thorac Surg 1974;17:450-8.

Cite this article as: Bonatti J, Wallner S, Crailsheim I, Grabenwöger M, Winkler B. Minimally invasive and robotic coronary artery bypass grafting-a 25 -year review. J Thorac Dis 2021;13(3):1922-1944. doi: 10.21037/jtd-20-1535
95. Wertheimer M, Liddle H. Results of direct coronary artery graft reconstruction a five-year clinical and arteriographic appraisal. Ann Thorac Surg 1975;20:538-49.

96. Coronary artery surgery study (CASS): a randomized trial of coronary artery bypass surgery. Survival data. Circulation 1983;68:939-50.

97. Myers WO, Davis K, Foster ED, et al. Surgical survival in the Coronary Artery Surgery Study (CASS) registry. Ann Thorac Surg 1985;40:245-60.

98. Øvrum E, Tangen G, Holen E. Facing the era of minimally invasive coronary grafting: current results of conventional bypass grafting for single-vessel disease. Ann Thorac Surg 1997;64:159-62.

99. O'Keefe JH Jr, Kreamer TR, Jones PG, et al. Isolated left anterior descending coronary artery disease: percutaneous transluminal coronary angioplasty versus stenting versus left internal mammary artery bypass grafting. Circulation 1999;100:II114-8.

100. Greenbaum AB, Califf RM, Jones RH, et al. Comparison of medicine alone, coronary angioplasty, and left internal mammary artery-coronary artery bypass for one-vessel proximal left anterior descending coronary artery disease. Am J Cardiol 2000;86:1322-6.

101.Farkouh ME, Domanski M, Sleeper LA, et al. Strategies for multivessel revascularization in patients with diabetes. N Engl J Med 2012;367:2375-84. 